JELTL (Journal of English Language Teaching and Linguistics) e-ISSN: 2502-6062, p-ISSN: 2503-1848

2019, Vol. 4(2)

www.jeltl.org

\title{
Supplementing Coursebooks-How, Why, and to What Effect: A Case Study
}

\author{
John Harper \\ Shantou University, China \\ e-mail:johnh@stu.edu.cn
}

\begin{abstract}
This article reports on a case study of one instructor's use of supplementary materials in an English as a Foreign Language course in China. Starting with the notion that no coursebook can be perfect and that supplementary materials therefore should form part of an English course, the study employed qualitative research methods to analyze the types of supplements used, the instructor's rationale behind his use of the supplements, and the students' interpretations of the supplements. Class observations, semi-structured interviews with the teacher, and focus-group discussions with students allowed for the triangulation of data. Findings indicated that the instructor provided a variety of types of supplementary materials in order to cater to different learner needs (specifically, affective needs, language-learning needs, course-content needs). While findings also indicated that learners generally appreciated the instructor's use of supplementary materials, significant mismatches between instructor goals and learner interpretations suggested that the purpose of the supplements was not always clearly defined. The article addresses these mismatches and provides suggestions for their future avoidance.
\end{abstract}

Keywords: affective factors, cognitive factors, intercultural communication, materials supplementation, perceptual mismatches

\section{INTRODUCTION}

During job interviews for the position of English as a Foreign Language (EFL) teacher of the English Language Center (ELC) of Shantou University (Guangdong Province, China), a frequently asked question is the following: "What coursebooks do you use?" This perfectly reasonable question is a testament to the ubiquitous nature of the coursebook in language teaching. As early as 1988, Sheldon pointed out the prevalence of coursebooks by simply 


\section{John Harper}

saying that "coursebooks are here" (p. 238, italics as in original). Hutchinson and Torres (1994), while noting various problems with a dependency on coursebooks, stated the obvious: "And yet the textbook not only survives, it thrives" (p. 316). Such comments came long before the days of complete course packages (i.e., DVDs, online activities, testgenerating software) that accompany today's coursebooks (see Littlejohn, 2011). It is thus not surprising that the coursebook, presently, often serves as the de facto curriculum (Guerrettaz \& Johnston, 2013) and that a great deal of what is done in the classroom now would not be possible without the commercial coursebook (Richards, 2001). However, there is still some doubt as to how much the coursebook should determine language teaching (Allen, 2015).

The controversy surrounding the presumed dependency on coursebooks in language teaching would seem to stem largely from the polemic regarding the advantages and disadvantages of coursebook use (see Maley, 2011; Richards, 1998). A frequent argument supporting coursebooks is that of time-saver. Given heavy workloads and often limited resources, teachers simply do not have time to devote to developing or looking for materials outside the coursebook. As Crookes (1997) notes, teachers rarely receive compensation for class preparation and thus go into survival mode and rely on the textbook to save themselves time and energy. Another argument in favor of coursebooks concerns quality. Sheldon (1998) refers to the "disconnected snippets" that teachers produce (p. 238). In a less derogatory fashion, Crawford (2002) notes that, in spite of modern technological advances, teachers often do not have access to the technology that would enable them to create materials that might compete with those of commercial coursebooks. Finally, the coursebook is known to create a ready-made map for teachers. It provides structure in terms of syllabus and sequence. Such structure aids teachers and learners (Hutchinson \& Torres, 1994; Richards, 1998) and is especially beneficial for less experienced teachers (Allen, 2015; McGrath, 2013).

The reliance on coursebooks in language teaching is of course not without its critics. A frequent complaint of coursebooks is that they may deskill teachers. Prahbu (1987) argues that "materials which are, or are made out to be, superior to what teachers can hope to do on their own, restrict the teacher to the role of a transmitter" (p. 95). In a similar vein, Nunan (1988) makes the point that "comprehensive, structured course materials" may deprive the classroom teacher of his/her role as a creative decision-maker (p. 99). An additional criticism put forth is that coursebooks, because of the time necessary for trialing and printing, necessarily lag behind developments in language-teaching research. Saraceni (2013), for example, notes that coursebooks continue to be based on the PPP (i.e., presentation, practice, production) format of language teaching even though such a format is not supported by current research (see also Shehadeh, 2005). Lastly, commercial coursebooks, especially those produced for a global audience, inevitably face difficulties in finding appropriate topics and in making appropriate cultural references. Acosta and Cajas (2018), in discussing imported commercial materials used in Ecuador, make the following comment: "[Students] would rather read a text about the Palacio Carondelet in Quito than about 10 Downing Street in London or the White House in Washington D.C." (p. 103). Oddly enough, when coursebooks seek to avoid inappropriate or inaccessible cultural references, they often end 
up presenting a rather dull world lacking in both controversy and excitement (see Richards, 2001; Saraceni, 2013; Tomlinson, 2013a).

Since the commercial coursebook, in spite of obvious drawbacks, exists as a central part of most teaching situations, it is not surprising that classroom teachers are called upon to take matters into their own hands by making the coursebook fit their particular circumstances. As a case in point, McGrath (2013) places the responsibility for materials use squarely on the classroom teacher: "teachers have two broad responsibilities in relation to materials: to evaluate them and to (re)design them" (p. 50). Reflective teachers, according to McGrath (2013), ensure that coursebook materials are adapted and/or supplemented so as to be relevant to and appropriate for a particular class within a particular context (see also McGrath, 2002).

Some published reports indicate that coursebook supplementation is especially well received by learners, yet evidence tends to be somewhat anecdotal (see Block, 1991; McGrath, 2013; Tomlinson, 2013b). Given the presence of the coursebook as a mainstay of most of today's language teaching, and given the fact that no coursebook can be perfect, the present case study sought to document, through an analysis of nine weeks of classroom teaching, how and why one English as a Foreign Language (EFL) teacher in China supplemented the coursebook and how learners responded to the teacher's supplementation.

\section{LITERATURE REVIEW}

\subsection{Terminological Confusion}

As McDonough, Shaw, and Masuhara (2013) and McGrath (2013) point out, the literature regarding ways in which teachers modify and/or add to coursebook materials contains some terminological confusion. The confusion lies principally in the distinction between materials adaptation and materials supplementation. Hence, some clarification of these terms is no doubt in order here so that the present focus on materials supplementation may proceed smoothly.

\subsubsection{Materials Adaptation}

Materials adaptation refers to the practice of making small omissions, additions, and/or modifications to existing materials, normally coursebook materials, in order to align them with a particular teaching context (McGrath, 2013; see also McDonough, Shaw, \& Masuhara, 2013; Richards, 2001). Islam and Mares (2003) offer an extensive list of reasons for adapting materials; some of the reasons given are the following:

- Methods (e.g., an exercise may be too mechanical, lacking in meaning, too complicated).

- $\quad$ Language content (e.g., there may be too much emphasis on grammar your students learn quickly or not enough emphasis on what they find difficult).

- Progression and grading (order of language items may need to be changed to fit an outside syllabus or the staging may need to be made steeper or more shallow).

- Cultural content (cultural references may need to be omitted or changed) (p. 88). 


\section{John Harper}

McDonough, Shaw, and Masuhara (2013), after citing Islam and Mares (2003), provide their own list, with some of the items being the following:

- Not enough grammar coverage in general.

- Reading passages contain too much unknown vocabulary.

- Comprehension questions are too easy, because the answers can be lifted directly from the text with no real understanding.

- Photographs and other illustrative material not culturally acceptable (p. 67).

Though neither list has been given in its entirety here, the samples provided should serve to illustrate the point that materials adaptation involves working with predetermined materials in order to gear them toward the pedagogical reality in which they will be used.

\subsubsection{Materials Supplementation}

McGrath (2002, 2013), while distinguishing supplementation from adaptation, recognizes that there is some overlap between the two. He envisions "a continuum of scale stretching from very simple forms of adaptation at one end to more extended forms of supplementation" (2013, p. 72). The primary distinction lies in the notion of "something new," a quality attributed to supplementation (McGrath, 2002, p. 80). Adaptation starts from coursebook materials and is based on those materials. Supplementation involves providing what is not supplied in the coursebook. Hence, supplementation may take one of two forms: (1) the use of materials from other published sources (i.e., sources other than the prescribed coursebook), (2) the use of teacher-designed materials (McGrath, 2002).

As supplementation presupposes the use of sources outside the prescribed coursebook, the teacher using supplementary materials faces the possibility of introducing a learning objective not included in the coursebook (McGrath, 2002). This possibility is not necessarily a problem, however. McGrath (2002) points out that supplementation arises out of the "recognition of a deficit" in coursebook materials (p. 80). The examples of deficits that McGrath (2002) provides are gaps between the coursebook and the prescribed syllabus, gaps between the coursebook and public examinations, and gaps between the coursebook and learner needs. Clearly, the last item (i.e., gaps between the coursebook and learner needs) may include almost anything (e.g., a lack of carefully scaffolded speaking practice with learners not accustomed to a communicative approach, a lack of authentic samples of a text genre useful for a particular group of learners). And as McGrath (2002) notes, supplementation may be based on learners' cognitive needs (e.g., critical thinking activities, activities designed to build vocabulary) or on learners' affective needs (e.g., warmup activities, activities designed simply to provide learners with something different). Of course, supplementary materials, ideally, would take into account both cognitive and affective factors.

\subsection{Materials Supplementation Studies}

As mentioned above, some discussions of coursebook supplementation have been rather anecdotal. Tomlinson (2013a), for example, recalls an incident in a Liverpool nightschool class for underprivileged students. Tired of enduring the irrelevance of a coursebook 
designed for middle-class learners, the instructor (i.e., Tomlinson himself) ordered the students to throw their coursebooks out of the windows of the classroom. As Tomlinson (2013a) puts it, "Now we had no irrelevant materials for the English class and, in fact, we had no materials at all. So, instead the students brought their own" (p. 139). Such a bold move had the effect of humanizing course materials - that is, of making them relevant and engaging for the learners as human beings with particular needs and particular life experiences.

Other studies regarding materials supplementation provide more documentation concerning how coursebook materials are supplemented. McGrath (2013) cites a study by Jazadi (2003) in which 106 Indonesian school teachers indicated how they supplemented coursebooks mandated by the Indonesian Ministry of Education. According to a survey, $74 \%$ of the teachers supplemented required coursebooks with privately published coursebooks on occasion while 11\% did so "most or all of the time" (McGrath, 2013, p. 143). Sixty-three percent of the teachers developed their own materials on occasion while $13 \%$ did so regularly. Teachers also reported other means of supplementation: "realia (56\%), materials from magazines $(41 \%)$, brochures and pamphlets (37\%), newspapers (35\%), audio cassettes accompanying coursebooks other than those prescribed (32\%) and coursebooks from other countries (25\%)" (McGrath, 2013, p. 143).

Katz (1996) analyzed the teaching practices of four composition instructors at an unspecified American university. The teachers, with minor exceptions, were using the same coursebooks, yet their classroom methods differed significantly. Using metaphors, Katz (1996) categorized the teachers as the choreographer, the earth mother, the entertainer, and the professor. Though the study was focused on teaching styles in general and not solely on materials supplementation, different preferences for materials supplementation appeared. The choreographer, for instance, designed checklists to help her students with essay revision; the entertainer designed an elaborate "song assignment" requiring students to choose a song, provide the lyrics of the song, write an essay about the song, and present their work to the class (p. 80). Classroom observations and interviews with the classroom teachers also allowed the author to obtain data concerning why the teachers supplemented as they did, with the choreographer, for example, stating that she wanted to lead learners through appropriate "learning steps" (Katz, 1996, p. 65).

Studies such as those of Jazadi (2003) and Katz (1996) shed light on how teachers supplement, and the Katz (1996) study provides insight as to why teachers supplement. These studies do not, however, provide insight as to the impact that such supplementation might have on learning, nor do they reveal the learners' perceptions of the materials. Acosta and Cajas (2018), in reporting the results of a survey administered to 65 English teachers of Ecuadorian tertiary institutions, provide their interpretation of how materials supplementation (or lack thereof) might impact student learning and motivation. Their study focused on the use of materials in the implementation of communicative language teaching (CLT). The findings indicate that Ecuadorian university teachers, at least some of the time, use supplementary materials, among which are transcripts from authentic audio texts for developing listening skills, pair-share activities for developing speaking skills, and communicative games for developing vocabulary. In spite of these findings, the authors lament the excessive dependence on imported coursebooks: 


\section{John Harper}

Too much dependence on textbooks...may deprive teachers [of] the ability to fulfil the very core principles of CLT. By relying on one aid, teachers lose the opportunity to use authentic materials and other resources. Further, the sole use of imported textbooks in classes may render the teaching-learning process insensitive to the context of students (Acosta \& Cajas, 2018, p. 108, italics mine).

Shawer, Gilmore, and Banks-Joseph (2008), focusing on teachers' implementation of a prescribed curriculum, report on their in-depth study of ten classroom teachers in Manchester, UK. The teachers fell into three categories: (1) curriculum-transmitters (i.e., those who simply taught the prescribed course without making any notable changes), (2) curriculum-developers (i.e., those who made use of various sources outside of the prescribed curriculum), (3) curriculum-makers (i.e., those who assessed learner needs in order to create a custom-made curriculum for their particular students). By interviewing both teachers and students, and by observing lessons, the researchers were able to triangulate data collectionthat is, to obtain data regarding the same phenomenon from multiple sources (see Denzin, 2009). According to research findings, the curriculum-developers and curriculum-makers, unlike the curriculum transmitters, frequently made use of supplementary materials (e.g., authentic videos, creative writing assignments, the packaging on food products). These teachers felt that their students showed significant learning gains, and their opinions were supported by observation reports. The students themselves often attributed their learning and their interest to their teachers' use of supplementary materials, with one saying that "the textbook was made in the past, but other materials are updated" and another simply stating that "relying on the book isn't enough" (Shawer, Gilmore, \& Banks-Joseph, 2008, p. 12).

\section{THE STUDY}

\subsection{Research Design}

This article reports the results of a case study carried out at the English Language Center (ELC) of Shantou University (STU) during the Spring Semester of 2019. The case study research option was chosen with two main goals in mind: (1) to get an in-depth view of one teacher's coursebook supplementation techniques and (2) to analyze the results of those techniques. As Tomlinson (2013b) notes, "pedagogy and materials cannot be researched or evaluated in isolation from their context of use... and effectiveness is variable rather than absolute" (p. 46). Hence, the study aimed to analyze the use of supplementary materials within a particular "context of use" and to consider the effectiveness of those materials within that context. A qualitative research method was used in order to allow data to emerge slowly throughout the semester and in order to allow data analysis to be refined throughout the process of data collection. There were no preconceived notions as to what types of supplementary materials should or should not be used. Though the opinions of the researcher (i.e., the author) were inevitably taken into account, they were of much less importance than those of the classroom teacher and those of the participating students. Three research questions guided the study:

1) How does the teacher supplement textbook materials?

2) Why does the teacher supplement textbook materials? 
3) How do learners respond to the teacher's supplementary materials?

As in the 2008 study by Shawer, Gilmore, and Banks-Joseph cited above, the research design used for the present study allowed for data triangulation. The research reported here, however, focused more specifically on the how and the why of materials supplementationthat is, how and why the teacher supplemented and how the teacher and the learners felt about the supplementation. The inclusion of learners' opinions was seen as furthering the studies (cited above) by Acosta and Cajas (2018), Jazadi (2003), and Katz (1996). Supplementary materials were coded and categorized not according to a preconceived notion but according to classroom moments as they evolved during the classroom experience. At first, categorization was somewhat ad hoc. Over time, however, certain general patterns emerged.

\subsection{Institutional Context}

Shantou University, a key provincial university in Guangdong Province, China, has a student body of roughly 10,000 , with some 8,000 students making up the undergraduate program, the program within which the present study was conducted. With the exception of students from the Medical College, the ELC offers English courses to all enrolled students. And with the exception of a few discipline-specific courses, most students of the undergraduate program complete a required four-semester, 16-credit suite of courses labeled ELC-1, ELC-2, ELC-3, and ELC-4. Classes meet twice a week for 90 minutes each time. The program in general is guided by the Five Golden Rules of English Learning: proficiency, autonomy, sustainability, intercultural competence, critical thinking skills.

All data reported here come from ELC-3, a course which focuses on intercultural communication. The basic description of the course, taken from the course syllabus, is the following: "This is a content-based integrated skills course focusing on intercultural communication and discussion skills." The syllabus also outlines specific content goals:

- To learn about the intercultural communication process and the factors that affect it.

- To build skills for responding to intercultural encounters.

- To learn about some basic aspects of Western culture.

- To build culture learning skills.

The standard coursebook for ELC-3 is Encounters with Westerners: Improving Skills in English and Intercultural Communication (Shanghai Foreign Language Education Press). The text is largely built around critical incident exercises (CIEs) - that is, exercises which "start with the presentation of a story describing a problematic encounter between people from two different cultures, an encounter in which there is some kind of cultural misunderstanding" (Snow, 2014, p. xiv; see also Spencer-Oatey \& Franklin, 2009). It also contains explanations of intercultural communication concepts (e.g., ethnocentrism, culture shock). Teachers of the course have access to a Moodle-based Teachers' Resource Sharing page containing optional supplementary materials designed by current and/or past teachers, and they also have the freedom to incorporate other supplementary materials into their lessons as they see fit. 


\section{John Harper}

\subsection{Participants}

Frank (not his real name), the teacher of the ELC-3 course from which all data were gathered, is a native speaker of English and a holder of an MA-TESOL degree. At the time of the study, he was in his fourth year at the ELC and also in his fourth year of full-time English teaching. He had just been promoted to the position of Lecturer. He was asked to participate in the study largely due to the researcher/author's belief that the good teacher does not necessarily need to be the most experienced teacher. Frank's role in the study was, first and foremost, to teach the course. He also needed to provide the researcher/author with lesson plans and supplementary materials before weekly observations and to participate in semi-structured interviews with the author/researcher after weekly observations. Frank signed a consent form agreeing to participate in the study.

The students (27 in total) were members of one of Frank's ELC-3 classes. They were of a variety of majors. Ten were females, and 17 were males. As class observation is standard ELC practice, the students did not need to sign a consent form for simply being observed. However, students selected to participate in focus groups (see following subsection) all signed consent forms agreeing to participate in the study. The role of focus-group members was to provide honest opinions concerning the use of supplementary materials in terms of both cognitive and affective factors.

\subsection{Data Collection}

Data for the study were collected from nine weeks of a 16-week semester. Data collection consisted of the following:

- weekly observation of one 90-minute ELC-3 lesson. No observation was conducted during the first week of the semester (in order to allow the teacher and the students to establish rapport without interference), and no observation was conducted during the seventh week (as the week was devoted to required mid-term examinations). Observations were carried out from the second week to the sixth week and, with one exception due to unforeseen circumstances, from the eighth week to the twelfth week. During observations, the researcher/author took copious field notes. These notes served as a guide for the researcher/author in preparation for semi-structured interviews with the classroom teacher and for focus-group discussions. They also allowed him to record visible learner reactions to supplementary materials.

- analysis of lesson plans and supplementary materials prior to observations. Lesson plans and supplementary materials were assumed to be subject to on-the-spot changes resulting from the dynamics of any particular lesson. Hence, the analysis of such documents prior to the lesson itself allowed the researcher/author to see how the original intentions of the teacher might be modified according to classroom-specific situational factors (see Bailey, 1996).

- weekly post-observation, semi-structured, recorded interviews between the classroom teacher and the researcher/author (henceforth, Teacher Interviews). These interviews allowed the researcher/author to obtain insights as to why the teacher chose to supplement the coursebook and how the teacher felt about the results of his supplementation. 
- five recorded focus-group discussions (FGDs) carried out at intervals during the semester. These discussions allowed the researcher/author to obtain insights as to how the learners themselves perceived supplementary materials. FGDs were intentionally carried out with different students each time, the result being that 23 out of 27 students were involved in a focus-group discussion at some point of the semester.

\section{FINDINGS AND DISCUSSION}

\subsection{Overview}

In the study discussed here, the instructor and the focus-group members generally coincided in their belief that supplementary materials had a positive effect on the ELC-3 course. However, data collected in Teacher Interviews and in FGDs revealed instances of what Kumaravadivelu (1991) terms "perceptual mismatches"-specifically, mismatches "between teacher intention and learner interpretation" (p. 101). The instructor tended to concentrate mainly (though not entirely) on matters of course content (i.e., on matters dealing with intercultural communication); students tended to view the materials and the tasks related to them mainly (though not entirely) in terms of language learning one the one hand and enjoyment through camaraderie on the other. This section will first categorize the types of supplements used and will then turn to an analysis of (1) the instructor's rationale behind his use of supplementary materials and (2) the students' interpretations of the use of supplementary materials. Perceptual mismatches will be pointed out in this section and will be discussed further in the Conclusion section of the article.

\subsection{Types of Supplements Used}

In describing the type of lesson that he has witnessed "over and over again," Tomlinson (2013b) notes that "most of the time the teacher and the students are looking at a textbook" (pp. 50-51). In the nine lessons observed for the purposes of the present study, such was hardly the case. The textbook served to provide a focus but certainly did not shackle the teaching-learning process. Frank, as the teacher of the course, tended to use the textbook in class about $30 \%$ of the time. One observation revealed an uncharacteristically large amount of textbook use (80\%), and two revealed no use of the textbook at all. It would be safe to say, then, that supplementary materials played a large role in the course observed. These materials generally fell into three overarching categories: (1) warmup activities, (2) reinforcement activities, (3) projects. These broad categories lent themselves to division into several subcategories, as the following will reveal:

\section{- warmups:}

- word-play activities (cartoons or riddles containing word play and requiring students to provide interpretations)

- schema-building activities (activities designed to lead students to discover a concept before it had been formally presented-e.g., a brief role play in which pairs of students received conflicting roles as an introduction to the concept of culture shock)

- review activities (activities in which students would quiz each other on previously studied vocabulary or would carry out brief discussions using previously studied vocabulary) 


\section{John Harper}

\section{- reinforcements:}

- supplementary readings (used to provide concrete examples of previously discussed intercultural communication concepts)

- listening activities (short, authentic videos or audios used to reinforce the understanding of intercultural communication concepts, with the term "authentic" being here defined as material originally intended for purposes other than language teaching [Nunan, 1988])

- the television series "Parenthood" (viewed outside of class and used to foster ongoing in-class discussions concerning the similarities and differences between Chinese culture and American culture)

- poster presentations/mind maps (used to lead students to delve further into previously discussed intercultural communication issues)

- online, ungraded quizzes (used to lead students to quiz themselves on their comprehension of course vocabulary)

\section{- projects:}

- writing assignments (two essays completed individually after extensive in-class preparation)

- Culture Smart Project (oral presentations in which pairs of students chose a nonEnglish-speaking country and presented an in-depth analysis of one aspect of that country)

- American Culture Project (oral presentations in which students worked in small groups to present an in-depth analysis of one aspect of American culture)

\subsection{Instructor Rationale for Use of Supplements}

As mentioned above, Teacher Interviews revealed that Frank tended to employ supplementary materials mainly in order to facilitate the learning of course content. The interviews, however, also revealed that he took into account affective factors and factors concerning the building of language skills. This section, then, will provide a brief description of how affective factors, language learning, and content learning were taken into consideration in the implementation of textbook supplements.

\subsubsection{Affective Factors}

A notable instance of Frank's considering affective factors came about in his discussion of his method of assigning the Culture Smart and American Culture Projects, both of which required students to work with classmates, to undertake research on culture issues, and to undergo the stress of oral presentations. The researcher/author, upon noticing that the instructions for these projects contained very little in the way of explanations of grading criteria, asked about the lack of focus on evaluation. Frank responded simply that evaluation was based on a pass-fail criterion (i.e., students do it or do not do it). Frank explained his rationale as follows:

I think...if I remove that pressure...it's just easier for students to focus on the content...the information. And it's in a way...I would hope...also motivating- 
motivating in terms of knowledge about a different culture... a different topic... and then also...you know...doing something using English (Teacher Interview, April 19, 2019).

Such a lax evaluation procedure comes across as rather unusual in China, a country well known for its high-stakes assessments (see Zhou, 2015). It reveals a belief that students, most of the time, will respond positively to a language-learning experience presented in a non-threatening manner (see Tomlinson, 2013b).

Frank's comments on specific classroom activities also revealed a focus on affective factors. In commenting on his use of word-play cartoons and riddles at the beginning of class, he pointed out that the goal was "to have fun with language rather than just saying, you know, this is vocabulary that we have to learn and practice, this is grammar that we have to learn and practice" (Teacher Interview, March 8, 2019). And in commenting on his motives for using a particular, vocabulary-oriented Find someone who activity in three consecutive semesters, he made the following statement: "It's the kind of activity where, when they do it, it's hard for me...hard for me as a teacher to get them to stop. So...it does seem very motivating for them" (Teacher Interview, April 12, 2019). In short, a language course, in Frank's view, should be an enjoyable experience, not a painful endeavor simply required by an institution.

\subsubsection{Language Learning}

In terms of promoting language learning, Frank once again went against the testoriented approach which, according to much research, is prevalent in China (see Zhou, 2015). His approach to writing assignments revealed a teacher-prompted innovation which put language learning far ahead of evaluation:

When I first started teaching the course, uhmm...[the students] would do the in-class writing...you know.... I would treat it more like a test in that they would just be writing...uhmm...their response to a critical incident. And I always had issues...well, the students would have issues...with the structure of the essay. So...uhmm...maybe the whole raw structure was just not on target. Last semester and this semester, I've made a point of letting them still see the copy of the sample essay as they're writing, and that solved the issues that the students had (Teacher Interview, March 29, 2019).

Hyland (2013) makes the point that "writing instruction will be more successful if students are aware of what target texts look like" (p. 392). Frank would seem to agree with this point. His strategic use of supplementary model essays indicates a focus on giving students an "expectancy of success," a focus which is critical in motivating language learners (Dörnyei, 2001, p. 57). And his experience in using the strategy has taught him that it does in fact lead students toward greater success.

Frank's concern with building students' language skills was also apparent in his discussions of particular classroom activities. Role plays, for example, were seen as activities which "push you to say things you normally wouldn't say" (Teacher Interview, March 29, 2019). Such activities, then, were intended to serve the purpose of stretching the learners' interlanguage capacity (see Skehan, 1998). Yet another focus on developing students' language ability was seen in rather frequent activities designed to review 


\section{John Harper}

vocabulary. One such activity was a rather straightforward discussion in which previously studied vocabulary appeared in a personalized context. In reviewing the word combinations burn out and struggle to (among others), Frank provided a handout with the questions "Do you already feel burned out at this point in the semester?" and "Are you struggling to wake up in time for English class?" (italics as in original course supplement). The terms burn out and struggle to had been originally presented in the textbook in the context of cultural adaptation. Ideally, the italics in the questions should have served to lead students to pay special attention to the terms, and the provision of a novel context should have stretched the students' knowledge of the meaning of the terms (see Nation, 2013). And by inviting students to make use of the terms in their discussion, the questions provided opportunities for "productive generative use" of vocabulary (Nation, 2013, p. 355). Frank rather succinctly summed up the rationale behind the activity: "I'm checking to see if they know what [a term] means...if they're able to use it on their own" (Teacher Interview, March 8, 2019).

\subsubsection{Intercultural Communication Training}

At the beginning of the present research project, when asked about his primary motives for using supplementary materials, Frank revealed a strong emphasis on intercultural communication-based course content:

Uhmm. I'd say...if I'm trying to find examples of concepts or ideas...uhmm...that are mentioned in the book, you know, there might be no specific examples. So...there's an article that we read...this past Monday... about culture... and they give advice about, you know, about not making judgments, not making generalizations about cultures. Uhmm. Instead of making judgments, you make descriptions about what people do in a different culture or...uhmm...you know, why people think a certain way or behave in a certain way. But they don't give examples... or any specific examples. What does a description of a culture look like? (Teacher Interview, March 8, 2019).

In making this comment, Frank echoes the reason for materials supplementation found in McGrath (2002): The primary motive is the discovery of a "deficit" (p. 80). In this case, the "deficit" relates to the lack of specificity found in the coursebook. Particular supplements used in the course reflected Frank's view. Hence, a video containing a young ChineseAmerican lad discussing stereotypes was intended to provide concrete examples of common stereotypes, and a video making specific contrasts between individualism and collectivism was implemented in order to lead students "to puzzle over...uhmm...what these two ideas, individualism and collectivism, are about" (Teacher Interview, March 15, 2019).

Throughout course, the instructor's interest in prompting students to consider matters of intercultural communication in depth was apparent, as the practice of having students produce visual products revealed. A small-group-designed poster presentation indicating ways of avoiding culture shock in Shantou was intended to serve the purpose of making students "think more deeply about the issue" (Teacher Interview, March 8, 2019). The purpose of a mind map illustrating the concept of face, saving face, and giving face in Chinese culture was, according to Frank, to encourage students to provide more detail about the concepts being considered. It would stand to reason that the learners, by going into greater detail, obtained useful practice in terms of language skills. The point here, however, 
is that intercultural communication-based content was the instructor's principal goal in implementing such activities.

\subsection{Student Interpretation of Use of Supplements}

Students participating in FGDs, like the instructor, revealed a concern with affective factors, language learning, and intercultural communication. However, as mentioned above, FGDs tended to indicate that students were more concerned with language learning and affect (especially enjoyment through camaraderie) than with intercultural communication. Here the students' opinions related to all three categories will be addressed. In cases in which students' views differed significantly from those of the instructor, these differences will be pointed out.

\subsubsection{Affective Factors}

The importance that students gave to enjoyment through camaraderie was apparent throughout the FGDs. In the very first FGD, one student, Tina, made the following comment: "Uhmm. In our group, we have become more familiar with each other, and when we discuss, we will enjoy it. But sometimes we didn't take it seriously...uhmm...because we will come up with ideas which is...uhmm...stupid" (FGD, March 13, 2019). Some five weeks later, another FG member, Julia, echoed Tina's idea that familiarity breeds camaraderie which in turn breeds enjoyment: "I think at first, when all the people are not familiar, I will feel a little bit embarrassed. But later on, I feel it is great for me to discuss with the people in the class" (FGD, April 20, 2019). And even later, yet another FG member, Christy, made the following comment:

We also communicate with each other out of class. So...the relationship between us...I think...is good. And...so...in class...when Frank ask some questions and asks us to discuss,... sometimes in one question we discuss it for...for some time. Then, the topic will change, and we talk more (FGD, May 11, 2019).

The comments above would seem to indicate that, for the students, one major goal of classroom activities is that of making friends (see Dörnyei \& Murphey, 2003). Regarding the students' admitted tendency to go somewhat off topic, one could argue that the students do not actually complete tasks according to task design but instead discuss matters of personal interest (see Seedhouse, 2005). Other comments from students, however, indicate that the positive relationship among classmates tended to have a positive effect on task outcomes. The FG member Bruce, for example, pointed out the following: "I think all of the groupmembers is nice. So... when I come out with some ideas, I will talk about it straightly, and I think.... So...I think it actually help to work better" (FGD, May 11, 2019). Another student, Bettina, in discussing the design of a poster presentation, noted that effective teamwork allowed for effective cooperation in carrying out a task:

I'm not good at drawing or painting or any other arts. So...most of the time I just figure out the explanation or the point. So...I think this kind of activity...uhh...it depends on teamwork. I come up with some ideas, and they [i.e., more artistically inclined partners] convey it through drawing some pictures. Also, I think it can just 


\section{John Harper}

practice our...our oral English because we should explain it to other people-explain our theory to our classmates (FGD, March 29, 2019).

An interest in enjoyment through camaraderie, then, does not necessarily hinder task performance and may even enhance it.

There were, incidentally, cases in which the students' focus on enjoyment through camaraderie seemed somewhat out of line with the instructor's goal for particular activities. As a case in point, the personalized vocabulary review (discussed above) was for the instructor a language-learning exercise intended to see if learners knew the meaning of the terms and could use them accurately. In commenting on such activities, one student, Christy, stated simply that " $[\mathrm{t}]$ he word combinations is easy, and we can all work out a sentence with them" (FGD, May 11, 2019). The students focused more on the social aspect of the activity, with one commenting that "it's interesting to know others' opinion is different from mine" and then adding that "I become more enjoy this part with my classmates" (Julia, FGD, April 20, 2019). Similarly, while the instructor's use of role play was intended to present intercultural conflict and to "push you to say things you normally wouldn't say," the students tended to see such activities mainly (but not entirely) as fun, as the following excerpt concerning a particular role-play activity will reveal:

Sarah: I enjoyed it because I think I got some fun from that part. And we can...can walk around and chat with others and pretend to be people of the culture. It's like an actor or actress. I enjoyed the feeling.

Bettina: I like to make friends with different kinds of people and different kinds of culture. I think it's really enjoyable. But why other people liked it too? I think it's because we are all curious, and we are curious to our new...new characters, and we are curious to other characters. So...we can, through communication with each other,...we can know more about other cultures and how we can express ourselves with our own [simulated] cultures. And with these new characters, I can communicate in a different way. So...I think it's challenging, and it's meaningful (FGD, March 29, 2019).

Though both Sarah and Bettina emphasized enjoyment and interest in communicating with their classmates, Bettina's comments also revealed an underlying awareness of the intercultural communication aspect (e.g., "express ourselves with our own [simulated] cultures") and of language goals (e.g., "communicate in a different way"). It is possible, then, that the students' focus on enjoyment through camaraderie, by leading them to embrace the activity wholeheartedly, may have led them more thoroughly to fulfill the instructor's goals for the task.

\subsubsection{Language Learning}

As mentioned above, the instructor allowed students to view a model essay during their own in-class writing. He did so in part in response to his noticing, in previous courses, that "the whole raw structure [of students' essays] was just not on target." He felt that, by letting the students see the sample, he had been able to give the learners a clearer focus. All FG members who commented on their writing were in agreement with Frank's view. Some students felt that the instructor's method had enabled them to feel comfortable with essay 
structure and thus to focus more on message. One mentioned that it helped her overcome a tendency to use Chinese essay structure in English essays. Yet another, White, seemed to feel a sense of relief:

When Frank asks us to write an essay, I have no idea what to write. And Frank gives us a structure, and I think "Oh, yeah! I got something I can write." I think writing is so difficult for me. I think asking me to write an essay is so embarrassing. My writing is so poor. And Frank gives us a structure, and I feel "Oh, thank God." I get something I can use...I can use in my essay. So...I will try my best to...just to follow the structure and to write the essay. Mmm. I think it's really helpful for me (FGD, March 30, 2019).

As mentioned earlier, one of Frank's motives in allowing students to view the sample essay while composing seemed to be that of providing students with an "expectancy of success." White's comments, like Frank's comments given previously, seem to indicate that Frank's method did indeed serve its purpose.

If in the present study it may be said that the interpretations of the instructor and the students concerning writing supplements produced an almost perfect perceptual match, it may also be said that the interpretations of listening supplements produced a rather large mismatch. As mentioned above, Frank's use of listening supplements stemmed from a desire to provide specific examples of intercultural communication concepts. FG members, however, tended to view such supplements as possible opportunities for the development of listening skills. Only in FGDs concerning listening tasks were students somewhat critical of the instructor's methods. One FG member, for example, made the following comment: "After we listen to the video twice, we only check the answers and nothing can make me listen clearly. I still didn't know what happened" (Rick, FGD, March 13, 2019). Another student, a participant in the same discussion, pointed out that "the teacher hasn't tell us many skills and...uhmm...tips to get better" (Sunny, FGD, March 13, 2019). In a much later FGD, the student Nick revealed a sort of resignation concerning listening activities: "Sometimes, it's just for fun to watch it...not for...not for learn something like pronunciation or words in the video" (FGD, April 20, 2019).

Such comments, viewed in the context of the instructor's goals for listening activities, indicate a rather clear "pedagogic" mismatch — that is, a mismatch related to "teacher/learner perceptions of stated or unstated short- and/or long-term objective(s) of language-learning tasks" (Kumaravadivelu, 1991, p. 102). The instructor's goal (i.e., to enhance knowledge of course content) seemed not to lend itself to satisfying the learners' goal (i.e., to enhance listening skills).

\subsubsection{Intercultural Communication Training}

In the example of a role play mentioned above, it was suggested that intercultural communication training goals may be reached even when the students' focus is more on enjoyment through camaraderie. Specifically, the FGD member Bettina acknowledged that the carrying out of a role-play task led her to "know more about other cultures and how we can express ourselves with our own [simulated] cultures." Such a comment, taken as one example among many, reveals that students were not oblivious to the intercultural communication goals of the course or of particular supplementary materials. Other 


\section{John Harper}

comments by FGD participants also indicated that students understood and, to some extent, benefitted from the intercultural communication focus. The following excerpts should serve as examples:

I think the class is focused on how to communicate with people from different cultures. So...I think we need more thinking and discussion in class. During the discussion with my group members, we can...uhh...we can find more new...uhh...thinking. So...I think it's better than just learning things from the textbook and remembering new words (Flash, FGD, March 30, 2019).

I think that doing the activities can make us better to...uhh...to comprehend the textbook. ELC-3 is about countries and culture. Maybe it's difficult for us to understand the textbook, sometimes, because it's different culture and also some misunderstanding the textbook. So...doing these activities can help us to understand it better and avoid misunderstanding (Christy, FGD, May 11, 2019).

When asked to comment on ways in which the Culture Smart Project may have helped him in terms of intercultural communication, the FGD member Charlie stated that "it will at least make me see the other country in a new aspect" (FGD, April 20, 2019).

The preceding student comments are obviously quite vague. This vagueness, prevalent throughout FGDs related to intercultural communication training, might be attributed to various factors (e.g., the abstract nature of the discipline, the fact that the students had never before taken a course centered around culture-related issues). The final FGD, however, provided specific insights as to why comments concerning intercultural communication tended to be vague. In discussing the value of intercultural communication-based supplements, Charlie stated the following: "What we learn is the different culture. But we are all from China, so it's almost always the same thing. It's almost always the same. So...I think it's...uhmm...good for practice English" (FGD, May 11, 2019). Charlie's statement was then echoed by Christy: "I think it can practice my English. But...in culture...all of us are Chinese, so it's hard to...hard to have some culture shock" (FGD, May 11, 2019). In short, the students tended to view intercultural communication training as being "peripheral to the 'real business' of language instruction" (Kearney, 2010, p. 332), and they also seemed to view the homogenous groupings typical of the EFL classroom as being less than ideal for the acquisition of intercultural communication skills.

\section{CONCLUSION}

This article has presented a case study of the use of supplementary materials in an EFL class taught in China. It has shown how and why one teacher supplements the coursebook in order to provide students with a learning experience beyond that provided in the coursebook itself. Specifically, it has shown that a teacher may provide many different types of supplements (e.g., role plays, projects, listening tasks) and, in doing so, may seek to serve different learner needs (i.e., affective needs, language-learning needs, course-content needs). Additionally, by directly taking into account learner reactions to supplementary materials, the article has moved beyond the tendency to describe learners' feelings about materials simply through teachers' interpretations of those feelings (see McGrath, 2013). 
The findings presented here indicate that the instructor of the course certainly does not feel bound by the textbook in any way. The sheer variety of types of supplementary materials used reveal a teacher constantly on the lookout for ways to improve his course. The findings, on the whole, indicate that students' appreciation of the course was enhanced in part due to the supplementary materials employed therein. Nevertheless, the study points out some significant perceptual mismatches between the instructor and the learners regarding the purpose of supplementary materials. Such mismatches confirm that "one answer to the question of why learners do not learn what teachers teach is that they come into the classroom with different mind sets, different points of focus, or...different agendas" (Nunan, 1995, p. 140). In the study reported here, learners emphasized language learning and enjoyment through camaraderie; the instructor emphasized intercultural communication. While in some cases these distinct emphases may have complemented one another, such was clearly not the case with listening activities.

The implications of these findings would seem to be rather clear. Teachers benefit their students by going out of their way to find or design supplementary materials to fit students' needs. Learners generally appreciate the supplementary materials provided by the teacher. This appreciation, however, must be analyzed from the students' perspective if the teacher wants to ensure that supplements serve the purpose that they are intended to serve. A task that is considered fun may be appreciated but may or may not aid in the attainment of learning goals. A task that seems to serve the teacher's purpose may leave learners feeling that their purpose for the task has been overlooked and that the task may therefore only be fun. Clearly, then, if supplementary materials are meant to further course goals by filling a gap in the coursebook, these materials will need to be jointly evaluated in ongoing dialogue between the teacher and the learners. Only then can the teacher know that his/her materials truly serve their intended purpose.

\section{REFERENCES}

Acosta, H. \& Cajas, D. (2018). Analysis of teaching resources used in EFL classes in selected Ecuadorian universities. Indonesian Journal of Applied Linguistics, 8(1), 100109.

Allen, C. (2015). Marriages of convenience? Teachers and coursebooks in the digital age. ELT Journal, 69(3), 249-263.

Bailey, K. M. (1996). The best laid plans: Teachers' in-class decisions to depart from their lesson plans. In K. M. Bailey \& D. Nunan (Eds.), Voices from the language classroom (pp. 15-40). Cambridge, UK: Cambridge University Press.

Block, D. (1991). Some thoughts on DIY materials design. ELT Journal, 45(3), 211-217.

Crawford, J. (2002). The role of materials in the language classroom: Finding the balance. In J. C. Richards \& W. A. Renandya (Eds.), Methodology in language teaching: An anthology of current practice (pp. 80-95). Cambridge, UK: Cambridge University Press.

Crookes, G. (1997). What influences what and how second and foreign language teachers teach? The Modern Language Journal, 81(1), 67-79.

Denzin, N. K. (2009). The research act: A theoretical introduction to sociological methods. New York, US: Aldine Transaction. 
Dörnyei, Z. (2001). Motivational strategies in the language classroom. Cambridge, UK: Cambridge University Press.

Dörnyei, Z., \& Murphey, T. (2003). Group dynamics in the language classroom. Cambridge, UK: Cambridge University Press.

Guerrettaz, A. M., \& Johnston, B. (2013). Materials in the classroom ecology. The Modern Language Journal 97(3), 779-796.

Hutchinson, T., \& Torres, E. (1994). The textbook as agent of change. ELT Journal, 48(4), 315-328.

Hyland, K. (2013). Materials for developing writing skills. In B. Tomlinson (Ed.), Developing materials for language teaching ( $2^{\text {nd }}$ ed., pp. 391-405). London, UK: Bloomsbury.

Islam, C., \& Mares, C. (2003). Adapting classroom materials. In B. Tomlinson (Ed.), Developing materials for language teaching. (pp. 86-100). London, UK: Continuum.

Jazadi, I. (2003). Mandated English teaching materials and their implications to teaching and learning: The case of Indonesia. In W. Renandya (Ed.), Methodology and materials design in language teaching: Current perspectives and practices and their implications. Anthology Series 44. (pp. 142-160). Singapore: SEAMO Regional Language Centre.

Kearney, E. (2010). Cultural immersion in the foreign language classroom: Some narrative possibilities. The Modern Language Journal, 94(2), 332-336.

Katz, A. (1996). Teaching style: A way to understand instruction in language classrooms. In K. M. Bailey \& D. Nunan (Eds.), Voices from the language classroom (pp. 57-87). Cambridge, UK: Cambridge University Press.

Kumaravadivelu, B. (1991). Language-learning tasks: Teacher intention and learner interpretation. ELT Journal, 45(2), 98-107.

Littlejohn, A. (2011). The analysis of language teaching materials: Inside the Trojan Horse. In B. Tomlinson (Ed.), Materials development in language teaching $\left(^{\text {nd }}\right.$ ed., pp. 179211). Cambridge, UK: Cambridge University Press.

Maley, A. (2011). Squaring the circle-Reconciling materials as constraint with materials as empowerment. In B. Tomlinson (Ed.), Materials development in language teaching $\left(2^{\text {nd }}\right.$ ed., pp. 379-402). Cambridge, UK: Cambridge University Press.

McDonough, J., Shaw, C., \& Masuhara, H. (2013). Materials and methods in ELT (3 ${ }^{\text {rd }}$ ed.). New York, US: Wiley-Blackwell.

McGrath, I. (2002). Materials evaluation and design for language teaching. Edinburgh, UK: Edinburgh University Press.

McGrath, I. (2013). Teaching materials and the role of EFL/ESL teachers: Practice and theory. London, UK: Bloomsbury.

Nation, P. (2013). Materials for teaching vocabulary. In B. Tomlinson (Ed.), Developing materials for language teaching ( $2^{\text {nd }}$ ed., pp. 351-364). London, UK: Bloomsbury.

Nunan, D. (1995). Closing the gap between learning and instruction. TESOL Quarterly, 29(1), 133-158.

Nunan, D. (1988). The Learner-centred curriculum. Cambridge, UK: Cambridge University Press.

Prabhu, N. S. (1987). Second language pedagogy. Oxford, UK: Oxford University Press. 
Richards, J. C. (1998). Beyond training. Cambridge, UK.: Cambridge University Press.

Richards, J. C. (2001). Curriculum development in language teaching. Cambridge, UK: Cambridge University Press.

Saraceni, C. (2013). Adapting courses: A personal view. In B. Tomlinson (Ed.), Developing materials for language teaching ( $2^{\text {nd }}$ ed., pp. 49-62). London, UK: Bloomsbury.

Seedhouse, P. (2005). “Task” as research construct. Language Learning, 55(3), 533-570.

Shawer, S., Gilmore, D., \& Banks-Joseph, S. R. (2008). Student cognitive and affective development in the context of classroom-level curriculum development. Journal of the Scholarship of Teaching and Learning, 8(1), 1-28.

Shehadeh, A. (2005). Task-based language learning and teaching: Theories and applications. In C. Edwards \& J. Willis (Eds.), Teachers exploring tasks in English language teaching (pp. 13-30). London, UK: Palgrave Macmillan.

Sheldon, L. E. (1988). Evaluating ELT textbooks and materials. ELT Journal, 42(4), 237246.

Skehan, P. (1998). A cognitive approach to language learning. Oxford, UK: Oxford University Press.

Snow, D. (2014). Encounters with westerners: Improving skills in English and intercultural communication. Shanghai, China: Shanghai Foreign Language Education Press.

Spencer-Oatey, H., \& Franklin, P. (2009). Intercultural interaction: A multidisciplinary approach to intercultural communication. London, UK: Palgrave Macmillan.

Tomlinson, B. (2013a). Humanizing the coursebook. In B. Tomlinson (Ed.), Developing materials for language teaching ( $2^{\text {nd }}$ ed., pp. 139-155). London, UK: Bloomsbury.

Tomlinson, B. (2013b). Classroom research of language classes. In B. Tomlinson (Ed.), Applied linguistics and materials development (pp. 43-59). London, UK: Bloomsbury.

Zhou, N. (2015). Oral participation in EFL classroom: Perspectives from the administrator, teachers and learners at a Chinese university. System, 53(53), 35-46. 